\title{
Ökonomisches Prinzip
}

Das ökonomische Prinzip (Wirtschaftlichkeitsprinzip) gliedert sich in zwei Bereiche:

- Das Minimumprinzip bedeutet, dass mit minimalem Mitteleinsatz ein vorgegebenes Ziel erreicht werden soll.

- Das Maximumprinzip bedeutet, dass mit gegebenen Mitteln ein maximaler Erfolg erzielt werden soll.

Wichtig ist, dass die Ertragsgröße festgelegt wird. Inhaltsleer wäre die Aussage, dass man mit dem geringsten Mitteleinsatz einen maximalen Ertrag erreichen solle.

Beispiel Maximumprinzip: Ökonomisch im Sinne dieses Prinzips handelt der Student, der seine ganze Arbeitskraft auf das Studium konzentriert, um ein möglichst gutes Examen abzulegen. Überträgt man das ökonomische Prinzip auf den Bereich betriebswirtschaftlicher Betätigung, bedeutet es, dass mit einem bestimmten gegebenen Kosteneinsatz eine möglichst große Produktionsleistung zu erzielen ist.

Beispiel Minimumprinzip: Ökonomisch im Sinne dieses Prinzips handelt der Student, der lediglich bestehen möchte und nur die dafür unbedingt notwendige Zeit in sein Studium investiert. Überträgt man das ökonomische Prinzip auf den Bereich betriebswirtschaftlicher Betätigung, bedeutet es, dass eine bestimmte Leistung mit möglichst geringen Kosten zu erzielen ist. 